\title{
Connectedness in fuzzy closure space
}

\author{
U. D. Tapi , Bhagyashri A. Deole* \\ Department of Applied Mathematics and Computational Science Shri G. S. Institute of Technology and Science (M.P.), India \\ *Corresponding author E-mail: deolebhagyashri@gmail.com
}

Copyright $\odot 2014$ U.D.Tapi, Bhagyashri A. Deole. This is an open access article distributed under the Creative Commons Attribution License, which permits unrestricted use, distribution, and reproduction in any medium, provided the original work is properly cited.

\begin{abstract}
A fuzzy Čech closure space $(\mathrm{X}, \mathrm{k})$ is a fuzzy set $\mathrm{X}$ with fuzzy $\check{C}$ ech closure operator $\mathrm{k}$ : $\mathrm{I}^{\mathrm{X}} \rightarrow \mathrm{I}^{\mathrm{X}}$ where $\mathrm{I}^{\mathrm{X}}$ is a power set of fuzzy subsets of $X$, which satisfies $\mathrm{k}(\varnothing)=\emptyset, \lambda_{1} \leq \lambda_{2} \Rightarrow \mathrm{k}\left(\lambda_{1}\right) \leq \mathrm{k}\left(\lambda_{2}\right), \mathrm{k}\left(\lambda_{1} \cup \lambda_{2}\right)=\mathrm{k}\left(\lambda_{1}\right) \cup \mathrm{k}\left(\lambda_{2}\right)$ for all $\lambda_{1}$, $\lambda_{2} \in \mathrm{I}^{\mathrm{X}}$. A fuzzy topological space $\mathrm{X}$ is said to be fuzzy connected if it has no proper fuzzy clopen set. Many properties which hold in fuzzy topological space hold in fuzzy Čech closure space as well. A Čech closure space (X, u) is said to be connected if and only if any continuous map from $X$ to the discrete space $\{0,1\}$ is constant. In this paper we introduce connectedness in fuzzy Čech closure space.
\end{abstract}

Keywords: Connectedness in Fuzzy Čech Closure Space, Connectedness in Fuzzy Topological Space, Fuzzy Čech Closure Operator, Fuzzy Čech Closure Space, Fuzzy Topological Space.

\section{Introduction}

In 1965 Zadeh [1] in his classical paper generalized characteristic function to fuzzy set. Chang [2] in 1968 introduced the topological structure of fuzzy sets. Pu and Liu [3] defined the concept of fuzzy connectedness using fuzzy closed set. Lowen [4] also defined an extension of a connectedness in a restricted family of fuzzy topologies. Fuzzy Čech closure operator and fuzzy Čech closure space were first studied by A.S. Mashhour and M.H. Ghanim [5]. In this paper we introduce connectedness in fuzzy Čech closure space and study some of their properties.

\section{Preliminaries}

Definition 2.1 [6]: An operator $\mathrm{u}: \mathrm{P}(\mathrm{X}) \rightarrow \mathrm{P}(\mathrm{X})$ defined on the power set $\mathrm{P}(\mathrm{X})$ of a set $\mathrm{X}$ satisfying the axioms:

1) $\mathrm{u} \phi=\phi$,

2) $\mathrm{A} \subseteq \mathrm{uA}$, for every $\mathrm{A} \subseteq \mathrm{X}$,

3) $u(A \cup B)=u A \cup u B$, for all $A, B \subseteq X$.

is called a Čech closure operator and the pair $(\mathrm{X}, \mathrm{u})$ is a Čech closure space.

Definition 2.2 [7]: Let $\mathrm{X}$ is a non-empty fuzzy set. A function $\mathrm{k}$ : $\mathrm{I}^{\mathrm{X}} \rightarrow \mathrm{I}^{\mathrm{X}}$ is called fuzzy Čech closure operator on $\mathrm{X}$ if it satisfies the following conditions

1) $\mathrm{k}(\emptyset)=\varnothing$.

2) $\lambda \leq \mathrm{k}(\lambda)$, for all $\lambda \in \mathrm{I}^{\mathrm{X}}$.

3) $\mathrm{k}\left(\lambda_{1} \cup \lambda_{2}\right)=\mathrm{k}\left(\lambda_{1}\right) \cup \mathrm{k}\left(\lambda_{2}\right)$ for all $\lambda_{1}, \lambda_{2} \in \mathrm{I}^{\mathrm{X}}$.

The pair $(\mathrm{X}, \mathrm{k})$ is called fuzzy Čech closure space.

Definition 2.3 [8]: A fuzzy topological space $(X, k)$ is said to be connected if $X$ cannot be represented as the union of two non-empty, disjoint fuzzy open subsets of $\mathrm{X}$.

Definition 2.4 [9]: A Čech closure space $(X, u)$ is said to be connected if and only if any continuous map $f$ from $X$ to the discrete space $\{0,1\}$ is constant. A subset $A$ in a Čech closure space $(X, u)$ is said to be connected if $A$ with the subspace topology is a connected space. 
Definition 2.5 [10]: Given fuzzy topological spaces $(\mathrm{X}, \delta)$ and $(\mathrm{Y}, \gamma)$, a function $\mathrm{f}: \mathrm{X} \rightarrow \mathrm{Y}$ is

$\mathrm{F}$ - continuous if the inverse image under $\mathrm{f}$ of any fuzzy open set in $\mathrm{Y}$ is a fuzzy open set in $\mathrm{X}$; i.e., if $\mathrm{f}^{-1}(\mathrm{v}) \in \delta$ whenever $\mathrm{v} \in \gamma$.

\section{Connectedness in fuzzy closure space}

Definition 3.1: Let $\mathrm{X}$ is a nonempty fuzzy set .A function $\mathrm{k}$ : $\mathrm{I}^{\mathrm{X}} \rightarrow \mathrm{I}^{\mathrm{X}}$ is called fuzzy Čech closure operator on X. A fuzzy Cech closure space $(X, k)$ is said to be connected if and only if any F-continuous map $f$ from $X$ to the fuzzy discrete space $\{0,1\}$ is constant.

Example 3.2: Let $X=\{a, b, c\}$ be a non-empty fuzzy set. Define fuzzy Čech closure operator $\mathrm{k}: \mathrm{I}^{\mathrm{X}} \rightarrow \mathrm{I}^{\mathrm{X}}$ such that

$\mathrm{k}(\mathrm{x})=\quad \begin{cases}0_{X} ; & \mathrm{A}=0_{\mathrm{X}} . \\ 1_{\{\mathrm{b}, \mathrm{c}\}} ; & \text { if } 0<\mathrm{A} \leq 1_{\{\mathrm{b}, \mathrm{c}\}} \\ 1_{\{\mathrm{b}, \mathrm{c}\}} ; & \text { if } 0<\mathrm{A} \leq 1_{\{\mathrm{b}\}} \\ 1_{\{\mathrm{b}, \mathrm{c}\}} ; & \text { if } 0<\mathrm{A} \leq 1_{\{\mathrm{c}\}} \\ 1_{X} ; & \text { otherwise }\end{cases}$

$\operatorname{FOS}(X)=\{\{a\},\{b\},\{c\},\{a, b\},\{a, c\}, \varnothing, X\}$.

Then $(X, k)$ is called fuzzy Čech closure space. We define an F-continuous function $\mathrm{f}: \mathrm{X} \rightarrow\{0,1\}$ such that $\mathrm{f}^{-1}\{1\}=\{\mathrm{a}, \mathrm{b}\}=\{\mathrm{a}, \mathrm{c}\}=\{\mathrm{a}\}=\{\mathrm{b}\}=\{\mathrm{c}\}=\mathrm{X}, \mathrm{f}^{-1}\{0\}=\varnothing$.

Here function $\mathrm{f}$ is constant. Hence $(\mathrm{X}, \mathrm{k})$ is a fuzzy connected Čech closure space.

Example 3.3: Let $X=\{a, b, c\}$ be a non-empty fuzzy set. Define a fuzzy Čech closure operator $\mathrm{k}: \mathrm{I}^{\mathrm{X}} \rightarrow \mathrm{I}^{\mathrm{X}}$ such that

$$
\mathrm{k}(\mathrm{x})= \begin{cases}0_{\mathrm{X}} ; \quad \mathrm{A}=0_{\mathrm{X}} . \\ 1_{\{\mathrm{a}, \mathrm{b}\}} ; \text { if } 0<\mathrm{A} \leq 1_{\{\mathrm{a}\}} \\ 1_{\{\mathrm{b}, \mathrm{c}\}} ; \text { if } 0<\mathrm{A} \leq 1_{\{\mathrm{b}\}} \\ 1_{\{\mathrm{c}, \mathrm{a}\}}, \text { if } 0<\mathrm{A} \leq 1_{\{\mathrm{c}\}} \\ 1_{\mathrm{X}} ; & \text { otherwise. }\end{cases}
$$

$\operatorname{FOS}(X)=\{\{a\},\{b\},\{c\},\{a, b\},\{b, c\},\{a, c\}, \varnothing, X\}$.

Then $(\mathrm{X}, \mathrm{k})$ is called fuzzy Čech closure space. We define an F-continuous function $\mathrm{f}: \mathrm{X} \rightarrow\{0,1\}$ such that $\mathrm{f}^{-1}\{1\}=\{\mathrm{a}\}=\{\mathrm{b}\}=\{\mathrm{c}\}=\{\mathrm{a}, \mathrm{b}\}=\{\mathrm{b}, \mathrm{c}\}=\{\mathrm{c}, \mathrm{a}\}=\mathrm{X}, \mathrm{f}^{-1}\{0\}=\varnothing$. Here function $\mathrm{f}$ is constant. Hence (X, $\left.\mathrm{k}\right)$ is a fuzzy connected Cech closure space.

Theorem 3.4: A fuzzy Čech closure space $(X, k)$ is said to be disconnected if and only if there is a nonempty proper fuzzy subset of $X$, which is both fuzzy open and fuzzy closed.

Proof: Necessary: Let fuzzy Čech closure space $(X, k)$ is disconnected i.e. there exists an F-continuous function $\mathrm{f}: \mathrm{X} \rightarrow\{0,1\}$ is not constant. Consider a proper fuzzy subset $\lambda$ of $\mathrm{X}$ such that $\lambda=1-\delta$. Since $\lambda$ is fuzzy closed subset of $\mathrm{X}$ therefore $\delta$ is fuzzy open subset of X. But $\delta$ is also a fuzzy closed subset of fuzzy Čech closure space (X, k) therefore $\lambda$ is fuzzy open subset of $X$. Hence $\lambda$ is a clopen subset of $X$.

Sufficient: Let $\delta=\mathrm{X}-\lambda$, since $\lambda$ is a nonempty proper fuzzy subset of $\mathrm{X}$, so that fuzzy set $\delta$ is also nonempty. Consider an F-continuous function $\mathrm{f}: \mathrm{X} \rightarrow\{0,1\}$ such that $\mathrm{f}(\lambda)=0$ or $1, \mathrm{f}(\delta)=1$ or 0 that is an F-continuous function $\mathrm{f}$ is not constant. Hence $(\mathrm{X}, \mathrm{k})$ is fuzzy disconnected Čech closure space.

Theorem 3.5: A continuous image of a fuzzy connected Čech closure space is fuzzy connected Čech closure space.

Proof: Let fuzzy Čech closure space $(X, k)$ is connected and consider an F-continuous function $f: X \rightarrow f(X)$ is surjective. If $\mathrm{f}(\mathrm{x})$ is not fuzzy connected Čech closure space, then there would be an F-continuous surjection $\mathrm{g}$ : $\mathrm{f}(\mathrm{x}) \rightarrow$ $\{0,1\}$ so that the composite function gof: $\mathrm{X} \rightarrow\{0,1\}$ would also be an F-continuous surjection. It is contradiction to the connectedness of fuzzy Čech closure space $(X, k)$. Hence $f(x)$ is a fuzzy connected Čech closure space.

Theorem 3.6: The union of any family of fuzzy connected subsets of fuzzy connected Čech closure space with a common point is connected.

Proof: Let $\left\{\mathrm{X}_{\alpha}\right\}$ be a family of fuzzy connected subsets of fuzzy connected Čech closure space (X, $\left.\mathrm{k}\right)$ and $\mathrm{p} \in \mathrm{X}_{\alpha}$ for all $\alpha$. Let $f: \mathrm{UX}_{\alpha} \rightarrow\{0,1\}$ be any F-continuous map and $\mathrm{f}_{\alpha}: \mathrm{X}_{\alpha} \rightarrow\{0,1\}$ be the restriction of $\mathrm{f}$ to $\mathrm{X}_{\alpha}$. Since $\mathrm{f}_{\text {and }} \mathrm{f}_{\alpha}$ are 
F-continuous functions. Each $\mathrm{X}_{\alpha}$ is fuzzy connected Čech closure space so $\mathrm{f}_{\alpha}$ is constant. Now let $\mathrm{p} \in \mathrm{X}_{\alpha}, \mathrm{f}_{\alpha}\left(\mathrm{x}_{\alpha}\right)=\mathrm{f}(\mathrm{p})$, $\forall \alpha \Rightarrow \mathrm{p} \in \mathrm{U} \mathrm{X}_{\alpha}, \mathrm{f}\left(\mathrm{x}_{\alpha}\right)=\mathrm{f}(\mathrm{p})$ i.e. $\mathrm{f}$ is constant. Hence $\mathrm{UX}_{\alpha}$ is fuzzy connected Čech closure space.

\section{Connected subsets in a fuzzy closure space}

Definition 4.1:-If $A \subset X,(X, k)$ is a fuzzy Čech closure space, then $A$ is said to be a fuzzy connected subset of $X$ if $A$ is fuzzy connected space as a fuzzy subspace of X. If $A \subset Y \subset X$, then A is a fuzzy connected subset of the fuzzy Čech closure space $\mathrm{X}$ if and only if it is a fuzzy connected subset of the fuzzy subspace $\mathrm{Y}$ of $(\mathrm{X}, \mathrm{k})$.

Example 4.2: Let $X=\{a, b, c\}$ be a non-empty fuzzy set. Define fuzzy Čech closure operator $\mathrm{k}: \mathrm{I}^{\mathrm{X}} \rightarrow \mathrm{I}^{\mathrm{X}}$ such that

$$
\mathrm{k}(\mathrm{x})= \begin{cases}0_{\mathrm{X}} ; & \mathrm{A}=0_{\mathrm{X}} . \\ 1_{\{\mathrm{b}, \mathrm{c}\}} ; & \text { if } 0<\mathrm{A} \leq 1_{\{\mathrm{b}, \mathrm{c}\}} \\ 1_{\{\mathrm{b}, \mathrm{c}\}} ; & \text { if } 0<\mathrm{A} \leq 1_{\{\mathrm{b}\}} \\ 1_{\{\mathrm{b}, \mathrm{c}\}} ; & \text { if } 0<\mathrm{A} \leq 1_{\{\mathrm{c}\}} \\ 1_{X} ; & \text { otherwise. }\end{cases}
$$

$\operatorname{FOS}(X)=\{\{a\},\{b\},\{c\},\{a, b\},\{a, c\}, X, \varnothing\}$.

Then $(\mathrm{X}, \mathrm{k})$ is called fuzzy Čech closure space. We define an F-continuous function $\mathrm{f}: \mathrm{X} \rightarrow\{0,1\}$ such that $\mathrm{f}^{-1}\{1\}=\{\mathrm{a}, \mathrm{b}\}=\{\mathrm{a}, \mathrm{c}\}=\{\mathrm{a}\}=\{\mathrm{b}\}=\{\mathrm{c}\}=\mathrm{X}, \mathrm{f}^{-1}\{0\}=\varnothing$.

Here function $\mathrm{f}(\mathrm{x})$ is constant. Hence $(\mathrm{X}, \mathrm{k})$ is a fuzzy connected Čech closure space.

Consider a subset $\mathrm{Y}=\{\mathrm{a}, \mathrm{b}\}$ of X. Define a fuzzy Čech closure operator $\mathrm{k}_{\mathrm{Y}}: \mathrm{I}^{\mathrm{Y}} \rightarrow \mathrm{I}^{\mathrm{Y}}$ such that

$$
\mathrm{k}_{Y}(\mathrm{x})= \begin{cases}0_{X} ; & \mathrm{A}=0_{\mathrm{X}} . \\ 1_{\{\mathrm{a}, \mathrm{b}\}} ; & \text { if } 0<\mathrm{A} \leq 1_{\{\mathrm{a}\}} \\ 1_{\{\mathrm{b}\}} ; & \text { if } 0<\mathrm{A} \leq 1_{\{\mathrm{b}\}} \\ 1_{\mathrm{X}} ; & \text { otherwise }\end{cases}
$$

$\mathrm{FOS}(\mathrm{X})=\{\{\mathrm{a}\}, \mathrm{X}, \varnothing\}$. Here $\left(\mathrm{Y}, \mathrm{k}_{\mathrm{Y}}\right)$ is a fuzzy Čech closure space. We define an F-continuous function $\mathrm{f}: \mathrm{Y} \rightarrow\{0,1\}$ such that $\mathrm{f}^{-1}\{1\}=\{\mathrm{a}\}=\{\mathrm{X}\}, \mathrm{f}^{-1}\{0\}=\varnothing$.

Hence $\left(\mathrm{Y}, \mathrm{k}_{\mathrm{Y}}\right)$ is a fuzzy connected Čech closure subspace of fuzzy connected Čech closure space $(\mathrm{X}, \mathrm{k})$.

Theorem 4.3: If $(X, k)$ is a fuzzy Čech closure space and $A$ is a fuzzy connected subset of $X$ and $\lambda$ and $\delta$ are non-empty fuzzy open sets in X satisfying $\lambda+\delta=1$, then either $\lambda / A=1$ or $\delta / A=1$.

Proof: If $\mathrm{A}$ is a fuzzy connected subset of $\mathrm{X}$ than there exists a continuous function $\mathrm{f}: \mathrm{A} \rightarrow\{0,1\}$ is constant. Suppose there exists $\mathrm{x}_{0}, \mathrm{y}_{0} \in \mathrm{A}$ such that $\lambda\left(\mathrm{x}_{0}\right) \neq 1$ and $\delta\left(\mathrm{y}_{0}\right) \neq 1$. Then $\lambda+\delta=1$ implies that $\lambda / \mathrm{A}+\delta / \mathrm{A}=1$, where $\lambda / \mathrm{A} \neq 0, \delta / \mathrm{A} \neq 0$ which implies that $\mathrm{f}(\lambda) \neq \mathrm{f}(\delta)$ in A. So A is not a fuzzy connected Čech closure subset of $X$. Hence either $\lambda / A=1$ or $\delta / \mathrm{A}=1$.

Theorem 4.4: Let $\left\{A_{\alpha}\right\}_{\alpha \in \wedge}$ be a family of fuzzy connected subsets of fuzzy Čech closure space $(X, k)$ such that for each $\alpha$ and $\beta$ in $\wedge$ and $\alpha \neq \beta, \mu_{A \alpha}$ and $\mu_{A \beta}$ are not separated from each other. Then $\bigcup_{\alpha \in \wedge} A_{\alpha}$ is a fuzzy connected subset of fuzzy Čech closure space $(X, k)$.

Proof: Suppose $\mathrm{Y}=\mathrm{U}_{\alpha \in \wedge} \mathrm{A}_{\alpha}$ is not a fuzzy connected subset of $\mathrm{X}$ that is F-continuous function $\mathrm{f}: \mathrm{Y} \rightarrow\{0,1\}$ is not constant. Let there exists non-zero fuzzy open sets $a$ and $b$ in $Y$ s. t. $f(a) \neq f(b)$ and $a+b=1$.Fix $\alpha_{0} \in \wedge$. Then $A \alpha_{0}$ is $a$ fuzzy connected subset of $\mathrm{Y}$ as it is so in fuzzy Čech closure space

$(\mathrm{X}, \mathrm{k})$. Therefore by theorem 4.3, either $\boldsymbol{\mu}_{\mathrm{A} \alpha 0} / \mathrm{A} \alpha_{0}=\mathrm{a} / \mathrm{A} \alpha_{0}$ or $\boldsymbol{\mu}_{\mathrm{A} \alpha 0} / \mathrm{A} \alpha_{0}=\mathrm{b} / \mathrm{A} \alpha_{0}$. Without loss of generality assume that

$\boldsymbol{\mu}_{\mathrm{A \alpha} 0} / \mathrm{A} \alpha_{0}=\mathrm{a} / \mathrm{A} \alpha_{0}$

Define $\lambda$ and $\delta$ as $\lambda(\mathrm{x})=\mathrm{a}(\mathrm{x})$ if $\mathrm{x} \in \mathrm{Y}$ and $\lambda(\mathrm{x})=0$ if $\mathrm{x} \in \mathrm{X}-\mathrm{Y}$ and $\delta(\mathrm{x})=\mathrm{b}(\mathrm{x})$ if $\mathrm{x} \in \mathrm{Y}$ and $\delta(\mathrm{x})=0$ if $\mathrm{x} \in \mathrm{X}-\mathrm{Y}$.

By theorem 4.3,

$\mathrm{k}_{\mathrm{Y}}(\mathrm{a})=\mathrm{k}(\lambda) / \mathrm{Y}$ and $\mathrm{k}_{\mathrm{Y}}(\mathrm{b})=\mathrm{k}(\delta) / \mathrm{Y}$

So (1) implies that $\boldsymbol{\mu}_{\mathrm{A} \alpha 0} \leq \lambda$. Therefore

$\mathrm{k}_{\mathrm{Y}}\left(\boldsymbol{\mu}_{\mathrm{Aa} 0}\right) \leq \mathrm{k}(\lambda)$

Let $\alpha \in \wedge-\left\{\alpha_{0}\right\}$. Since $A_{\alpha}$ is a fuzzy connected closure subset of $Y$ either

$\boldsymbol{\mu}_{\mathrm{A} \alpha} / \mathrm{A}_{\alpha}=\mathrm{a} / \mathrm{A}_{\alpha}$ or $\boldsymbol{\mu}_{\mathrm{Aa} \alpha} / \mathrm{A}_{\alpha}=\mathrm{b} / \mathrm{A}_{\alpha}$, we show that $\boldsymbol{\mu}_{\mathrm{A \alpha}} / \mathrm{A}_{\alpha} \neq \mathrm{b} / \mathrm{A}_{\alpha}$.

Suppose that $\boldsymbol{\mu}_{\mathrm{A \alpha}} / \mathrm{A}_{\alpha}=\mathrm{b} / \mathrm{A}_{\alpha}$. Therefore $\boldsymbol{\mu}_{\mathrm{A} \alpha} \leq \delta$. Hence

$\mathrm{k}\left(\boldsymbol{\mu}_{\mathrm{A} \alpha}\right) \leq \mathrm{k}(\delta)$

This gives a contradiction as $\boldsymbol{\mu}_{\mathrm{A} \alpha 0}$ and $\boldsymbol{\mu}_{\mathrm{A} \alpha}$ are not separated from each other.

So $\boldsymbol{\mu}_{\mathrm{A} \alpha} / \mathrm{A}_{\alpha} \neq \mathrm{b} / \mathrm{A}_{\alpha}$. Hence $\boldsymbol{\mu}_{\mathrm{A} \alpha} / \mathrm{A}_{\alpha}=\mathrm{a} / \mathrm{A}_{\alpha}$ for each $\alpha \in \wedge$. Which implies that $\boldsymbol{\mu}_{\mathrm{Y}}=\mathrm{a}$. 
But $a+b=1$. So $b(x)=0$ for every $x \in Y$.But $b \neq 0$. So the supposition that $Y$ is not a fuzzy connected subset of $X$ is false i.e. F-continuous function $\mathrm{f}: \mathrm{Y} \rightarrow\{0,1\}$ is constant. Hence $U_{\alpha \epsilon \wedge} \mathrm{A}_{\alpha}$ is a fuzzy connected subset of fuzzy Čech closure space $(\mathrm{X}, \mathrm{k})$.

Theorem 4.5: If $\left\{A_{\alpha}\right\}_{\alpha \epsilon \wedge}$ is a family of fuzzy connected subsets of a fuzzy connected Čech closure space $(X, k)$ and $\cap_{\alpha \epsilon \wedge} A_{\alpha} \neq \emptyset$, then $U_{\alpha \epsilon \wedge} A_{\alpha}$ is a fuzzy connected subset of fuzzy connected Čech closure space $X$.

Proof: Let $\mathrm{A}_{\alpha}$ in the family is a fuzzy connected subset of fuzzy Čech closure space $(\mathrm{X}, \mathrm{k})$ i.e. A F-continuous function $\mathrm{f}:\left\{\mathrm{A}_{\alpha}\right\}_{\alpha \in \wedge} \rightarrow\{0,1\}$ is constant. For any $\alpha, \beta \in \wedge, \alpha \neq \beta$, we have $\mathrm{A}_{\alpha} \cap \mathrm{A}_{\beta} \neq \varnothing$. Hence $\mathrm{k}\left(\boldsymbol{\mu}_{\mathrm{A} \alpha}\right)+\boldsymbol{\mu}_{\mathrm{A} \beta}>1$

and $\boldsymbol{\mu}_{\mathrm{A} \alpha}+\mathrm{k}\left(\boldsymbol{\mu}_{\mathrm{A} \beta}\right)>1$. Thus characteristics functions of each pair of members of the family are not separated from each other. So $U_{\alpha \epsilon \wedge} A_{\alpha}$ is a fuzzy connected subset of fuzzy Čech closure space X.

Theorem 4.6: If $C$ is a fuzzy connected subset of a fuzzy connected Čech closure space $X, V \subset X-C$ and $\boldsymbol{\mu}_{v} / X-C$ is a fuzzy clopen in $X-C$, and then $C U V$ is a fuzzy connected subset of fuzzy connected Čech closure space $(X, k)$.

Proof: Suppose Y=CUV is not a fuzzy connected Čech closure subset of fuzzy connected closure space (X, k).Then there exist fuzzy open sets $\lambda$ and $\delta$ such that $\mathrm{f}(\lambda) \neq \mathrm{f}(\delta)$, and

$\lambda / \mathrm{Y}+\delta / \mathrm{Y}=1$

Since $\mathrm{C}$ is a fuzzy connected Čech closure subset of $\mathrm{Y}$ (as it is so in $\mathrm{X}$ ),

By theorem $4.3, \lambda / \mathrm{C}=\mu_{\mathrm{C}} / \mathrm{C}$ or $\delta / \mathrm{C}=\mu_{\mathrm{C}} / \mathrm{C}$.Without loss of generality assume that

$\lambda / \mathrm{C}=\mu_{\mathrm{C}} / \mathrm{C}$. So by equation (1),

$\delta / \mathrm{C}=0$

Therefore $\delta / \mathrm{V} \neq 0$ (as $\delta / \mathrm{Y} \neq 0)$

Let us define a fuzzy set $\delta_{1}$ in $\mathrm{X}$ as

$\delta_{1}(\mathrm{x})=\delta(\mathrm{x})$, if $\mathrm{x} \in \mathrm{V}$, $=0, \quad$ if $\mathrm{x} \in \mathrm{X}-\mathrm{V}$.

We shall now show that $\delta_{1}$ is fuzzy closed as well as fuzzy open in X.

Now $\delta_{1} / \mathrm{V}=\delta / \mathrm{V}$ and by equation (1) $\delta / \mathrm{V}$ is fuzzy closed in $\mathrm{V}$.

Therefore $\delta_{1} / \mathrm{V}$ is fuzzy closed in V. Also $\boldsymbol{\mu}_{\mathrm{v}}$ is fuzzy closed in X-C. Therefore $\delta_{1} / \mathrm{X}-\mathrm{C}$ is fuzzy closed in X-C. Now $\delta_{1} / \mathrm{X}-\mathrm{C}=\delta / \mathrm{X}-\mathrm{C} \cap \mu_{\mathrm{v}} / \mathrm{X}-\mathrm{C}$.

Therefore $\delta_{1} / \mathrm{X}-\mathrm{C}$ is fuzzy open in $\mathrm{X}-\mathrm{C}$.

Thus $\delta_{1} / \mathrm{X}-\mathrm{C}$ is fuzzy clopen in $\mathrm{X}-\mathrm{C}$

Further $\delta_{1} / \mathrm{Y}=\delta / \mathrm{Y}$ (because of (2)). As $\delta / \mathrm{Y}$ is fuzzy clopen in $\mathrm{Y}$ (because of (1)), therefore

$\delta_{1} / \mathrm{Y}$ is fuzzy clopen in $\mathrm{Y}$.

Now by (4) and (5) and $\delta_{1}$ is fuzzy clopen in (X-C) $\cup Y=X$. As $\delta_{1}$ is a proper fuzzy set, we get a contradiction to the fact that $\mathrm{X}$ is fuzzy connected Čech closure space. Hence CUV is a fuzzy connected subset of fuzzy connected Čech closure space $(\mathrm{X}, \mathrm{k})$.

Theorem 4.7: If $A$ and $B$ are fuzzy subsets of a fuzzy Čech closure space $(X, k)$ and $\boldsymbol{\mu}_{A} \leq \boldsymbol{\mu}_{B} \leq k\left(\boldsymbol{\mu}_{A}\right)$ and $A$ is fuzzy connected closure subset of $X$, then $B$ is also a fuzzy connected Čech closure subset of fuzzy Čech closure space (X, $k$ ).

Proof: If we suppose that B is not a fuzzy connected subset then there exist fuzzy open sets $\lambda$ and $\delta$ in $X$ such that $\lambda / \mathrm{B} \neq 0, \delta / \mathrm{B} \neq 0$, and $\mathrm{f}(\lambda) \neq \mathrm{f}(\delta)$

We first show that $\lambda / \mathrm{A} \neq 0$. If $\lambda / \mathrm{A}=0$, then $\lambda+\boldsymbol{\mu}_{\mathrm{A}} \leq 1$, which implies that $\lambda+\mathrm{k}\left(\boldsymbol{\mu}_{\mathrm{A}}\right) \leq 1$; so $\lambda+\boldsymbol{\mu}_{\mathrm{B}} \leq 1$

(because $\boldsymbol{\mu}_{\mathrm{B}} \leq \mathrm{k}\left(\boldsymbol{\mu}_{\mathrm{A}}\right)$ ). This is turn implies that $\lambda / \mathrm{B}=0$, which is a contradiction , as $\lambda / \mathrm{B} \neq 0$. Therefore $\lambda / \mathrm{A} \neq 0$.

Similarly we can show that $\delta / \mathrm{A} \neq 0$.Now (1) and $\boldsymbol{\mu}_{\mathrm{A}} \leq \boldsymbol{\mu}_{\mathrm{B}}$ imply $\lambda / \mathrm{A}+\delta / \mathrm{A}=1$. So $\mathrm{A}$ is not fuzzy connected, which is a contradiction.

\section{Conclusion}

In this paper the idea of connectedness in fuzzy Čech closure space was introduced and relationship between the connectedness and fuzzy Čech closure space were explained.

\section{References}

[1] L.A. Zadeh, Fuzzy sets, Inform. And Control 8 (1965) pp: 338-353.

[2] C.L. Chang, Fuzzy topological Space, J. Math. Anal. Appl., 24 (1968), pp: 182-190.

[3] P.M. Pu and Y. M. Liu, Fuzzy topology I. Neighbourhood structure of a fuzzy point and Moor- Smith convergence. J. Math. Anal. Appl., 76, (1980), pp: 571-599.

[4] R. Lowen, Fuzzy topological spaces and fuzzy compactness, J. Math. Anal. Appl. 56(1976), pp: 621-633.

[5] A.S. Mashhour, M.H. Ghanim, Fuzzy closure space, J. Math. Anal. Appl., 106, (1985), pp: 154-170. 
[6] C. Boonpok, On Continuous Maps in Closure Spaces, General Mathematics Vol. 17, (2009), No. 2.

[7] R. Gowri, G. Jegadeesan, Connectedness in fuzzy Čech closure spaces, Asian Journal of current engineering and maths 2:5, (2013) pp: 326328.

[8] K. S. Sethupathy Raja, S. Lakshmivarahan Connectedness in fuzzy topological space, Kybernetika- volume 13 (1977), number 3.

[9] U.D. Tapi, Bhagyashri A. Deole, note on connectedness in closure space, Impact J. Sci. Tech., Fiji Islands, Vol. 6, (2012), No. 1,pp: 43-46.

[10] K. K. Azad. On fuzzy semi continuity, fuzzy almost continuity and fuzzy weakly continuity, J. Math. Anal. Appl. 82(1) (1981), 14-32. 